\title{
A rare coexistence of non-functional adrenocortical carcinoma and multicentric papillary thyroid microcarcinoma: a case report
}

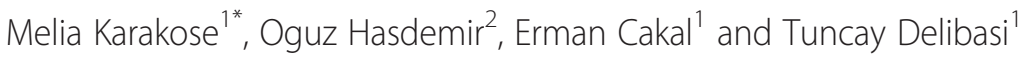

\begin{abstract}
Introduction: In this report, we describe a rare case of papillary thyroid carcinoma with adrenocortical carcinoma without excess hormone production.

Case presentation: A 40-year-old Turkish man was admitted to our institution with a large left adrenal mass that was identified during the work-up for shortness of breath. The patient did not have specific signs and symptoms of hormone excess. The mass was removed surgically. The pathological findings were consistent with adrenocortical carcinoma. The patient was also found to have a multicentric papillary thyroid microcarcinoma.

Conclusion: Most adrenocortical carcinomas and papillary thyroid carcinomas are sporadic; however, the occurrence of two different endocrine neoplasms during the same period of time is a rare situation, but it is possible, as in our patient. When an endocrine tumor is diagnosed, endocrinologists must be consider the possibility of the existence of another endocrine tumor.
\end{abstract}

Keywords: Adrenocortical carcinoma, Papillary thyroid carcinoma, Hormone

\section{Introduction}

Adrenocortical carcinomas (ACCs) are an extremely rare type of cancer with an incidence of less than 2 per 1 million worldwide [1,2]. Approximately $60 \%$ of patients present with symptoms of excess hormone secretion or manifest themselves as symptoms and signs due to mass effect. Thyroid cancer is the most common malignant endocrine tumor. Its annual incidence varies between 0.5 to 10 per 100,000 . Papillary thyroid carcinoma (PTC) is the most common form of differentiated thyroid carcinoma and is more common in women than in men. It is often diagnosed during investigation of a thyroid nodule in clinics.

There are few case reports in the literature that describe comorbid ACC and PTC. The available reports attribute the concomitant appearance of the tumors to coincidence and do not discount a potential genetic or hereditary link [3-5]. Herein we report a rare coexistence of PTC and ACC without clinical hormone excess.

\footnotetext{
* Correspondence: meliakarakose@yahoo.com

${ }^{1}$ Department of Endocrinology and Metabolism, Diskapi Yildirim Beyazit

Training and Research Hospital, Altindag, Ankara, Turkey

Full list of author information is available at the end of the article
}

\section{Case presentation}

A 40-year-old Turkish man who presented to our institution with shortness of breath was evaluated by computed tomography. A mass in his left adrenal gland was diagnosed incidentally. A magnetic resonance imaging (MRI) scan showed a large mass measuring $8 \times 9.5 \times 10.4 \mathrm{~cm}$ in diameter in the left adrenal gland area (Figure 1). His serum cortisol, adrenocorticotropic hormone, dehydroepiandrosterone sulfate, total testosterone, urinary metanephrine, serum electrolytes $\left(\mathrm{Na}^{+}, \mathrm{K}^{+}, \mathrm{Cl}^{-}\right)$, fasting blood glucose, and fasting insulin levels were normal. Plasma cortisol was suppressed after administration of $1 \mathrm{mg}$ dexamethasone. The patient was diagnosed with a non-functional adrenal mass, and a left adrenalectomy was performed. The resected tumor was $11 \times 9 \times 6 \mathrm{~cm}$ in size and weighed $339 \mathrm{~g}$. The tumor was of high nuclear grade and had diffuse architecture, focal necrotic areas, more than 5 mitoses per 50 high-power fields, and an infiltrated capsule. Sinusoidal vascular infiltration was observed, but clear cells were less than $25 \%$. Immunohistochemical studies showed that melan-A and inhibin were positive, and thyroid transcription factor-1 (TTF-1) and thyroglobulin were negative. The pathological findings 


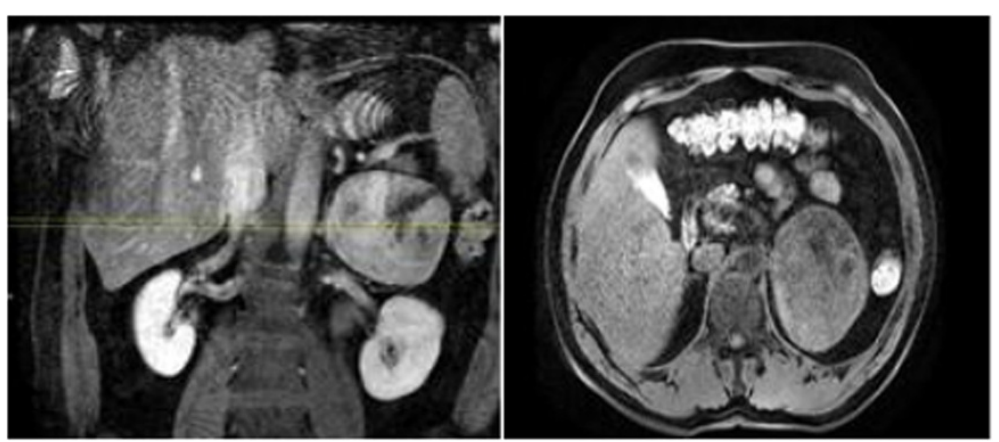

Figure 1 Dynamic magnetic resonance imaging scans (left adrenal mass).

were consistent with ACC. Treatment with adjuvant radiotherapy with concurrent mitotane was planned for the patient.

Evaluations of thyroid function tests were normal before treatment and anti-thyroglobulin antibody was positive, but anti-thyroperoxidase antibody was negative. Ultrasonographic evaluation of the thyroid revealed the following: There was a nodule $3 \times 4 \times 4 \mathrm{~mm}$ in size in the lower part of the left lobe and foci of microcalcification, and the edges were irregular and of mixed echogenicity.

The elastosonography score of the nodule was 5, and the strain index was calculated as 7.85 (Figure 2). The patient had neither a history of radiation exposure nor a family history positive for thyroid carcinoma. A fineneedle aspiration biopsy of the nodule was suspicious for malignancy. The patient underwent total thyroidectomy and central neck dissection. Tumors were detected in two foci with diameters of $0.9 \mathrm{~cm}$ and $0.4 \mathrm{~cm}$ in the left lobe. There was neither lymphovascular nor capsular invasion or lymph node metastasis. Immunohistochemical studies showed that thyroglobulin was positive. The pathologic diagnosis was multicentric papillary thyroid microcarcinoma.

\section{Discussion}

ACCs are a rare type of malignancy (incidence of 1 to 2 cases per 1 million population) with a heterogeneous presentation and generally have a poor prognosis $[1,6]$. Women are affected more often than men $[7,8]$. The diagnosis of malignancy of adrenocortical tumors depend on careful investigations of clinical, biological, and imaging features before surgery and pathological examination. The assessment of the Weiss score is important for the diagnosis of malignancy $[9,10]$. Adrenocortical tumors might be seen as a component of several hereditary tumor syndromes such as Li-Fraumeni syndrome, Beckwith-Wiedemann syndrome, multiple endocrine neoplasia 1, Carney complex, and congenital adrenal hyperplasia. A lot of specific genes might have a role in the pathogenesis of sporadic ACC, and some of them might be seen in the pathogenesis of the aforementioned syndromes $[11,12]$.

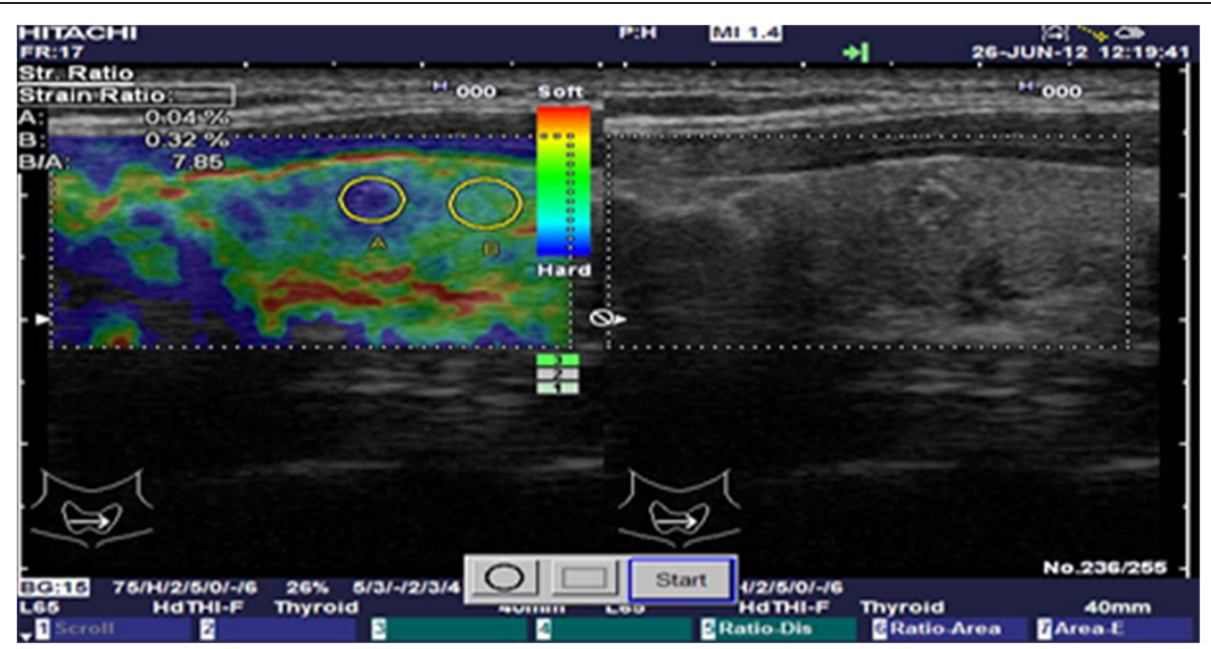

Figure 2 Elastosonographic and ultrasound images of the thyroid nodule. 
Patients present with evidence of adrenal steroid hormone excess in approximately $60 \%$ of cases. Rapidly progressing Cushing's syndrome with or without virilization is the most frequent presentation. Hormonal inactive ACC usually presents with abdominal discomfort (nausea, vomiting, and abdominal fullness) or back pain caused by a mass effect of the large tumor.

PTC comprises about $85 \%$ of cases with differentiated thyroid carcinoma [13]. PTC usually presents with a thyroid nodule or cervical lymphadenopathy. Nodules more than $1 \mathrm{~cm}$ in diameter have a greater potential to be malignant. On the other hand, patients with nodules less than $1 \mathrm{~cm}$ in diameter, suspicious ultrasound findings, lymphadenopathy, a history of neck and head irradiation, or a history of thyroid cancer in first-degree relatives must be evaluated for cancer [14].

The ultrasonographic features suggesting the presence of malignancy in a thyroid nodule have been described clearly. These include microcalcifications, marked hypoechogenicity, absent "halo" sign, extraglandular extension, an irregular or microlobulated margin, and a heterogeneous echo structure $[15,16]$. Individual sonographic features have limitations for prediction of thyroid cancer. Elastosonography is a newly developed, promising sonographic method for evaluating suspicious nodules. It gives information about the stiffness of a nodule by measuring the amount of distortion that occurs when the nodule is subjected to external pressure [17]. Tissue stiffness is scored from 1 to 5 based on subjective analysis of the elastographic image. Rago et al. reported sensitivity of $97 \%$ and specificity of $100 \%$ for a score of 4 or 5 as being predictive of malignancy [18].

PTC generally metastasizes to the lymph nodes. Distant organ metastasis is rare, but lung, bone, brain, liver, and adrenal gland metastases have been reported $[19,20]$. ACC may metastasize to the thyroid gland [21]. Immunohistochemical staining is used to differentiate the primary and metastatic tumors. Melan-A, inhibin, and some other markers have been found to be positive in patients with ACC [22-24], and thyroglobulin and TTF-1 have been found to be positive in patients with thyroid neoplasms in immunohistochemical studies [25-28]. In our case, melanA and inhibin were positive, but thyroglobulin and TTF-1 were negative, in the patient's adrenal gland tumor. The thyroid lesion was thyroglobulin-positive. Therefore, these lesions were evaluated as primary tumor neoplasms of those organs.

In the literature, there are few case reports of patients with with comorbid ACC and PTC. Fukushima et al. reported a case of a middle-aged woman with virilizing adrenocortical adenoma complicated with Cushing's syndrome, PTC, and hypergastrinemia [3]. They did not study genetic analyses in their patient. Wanta et al. reported the case of a patient with synchronous presentation of an aldosterone-secreting metastatic ACC and PTC [4]. That patient was diagnosed as having Li-Fraumeni syndrome and multiple endocrine neoplasia type I, but both $p 53$ and menin gene mutations were absent.

\section{Conclusion}

Herein we present a case of a patient with PTC and ACC without clinical hormone excess. Most ACCs and PTCs are sporadic; however, the possibility of a hereditary cancer syndrome could not be ruled out because of the co-occurrence of two different endocrine neoplasms within the same period of time. Therefore, when an endocrine tumor is diagnosed in a patient, endocrinologists must consider the possibility of the existence of another endocrine tumor.

\section{Consent}

Written informed consent was obtained from the patient for publication of this case report and any accompanying images. A copy of the written consent is available for review by the Editor-in-Chief of this journal.

\section{Competing interest}

The authors declare that they have no competing interests.

\section{Authors' contributions}

MK analyzed and interpreted the patient's data. The surgery was performed by $\mathrm{OH}$. EC and TD contributed to the writing of the manuscript's Discussion section. All authors read and approved the final manuscript.

\section{Author details}

${ }^{1}$ Department of Endocrinology and Metabolism, Diskapi Yildirim Beyazit Training and Research Hospital, Altindag, Ankara, Turkey. ${ }^{2}$ Department of General Surgery, Diskapi Yildirim Beyazit Training and Research Hospital, Altindag, Ankara, Turkey.

Received: 1 April 2013 Accepted: 18 June 2013

Published: 26 July 2013

\section{References}

1. Wajchenberg B, Albergaria PM, Medonca B, Latronico A, Campos CP, Ferreira AV, Zerbini M, Liberman B, Carlos GG, Kirschner M: Adrenocortical carcinoma: clinical and laboratory observations. Cancer 2000, 88:711-736.

2. Fassnacht M, Wittekind C, Allolio B: [Current TNM classification systems for adrenocortical carcinoma] [in German]. Pathologe 2010, 31:374-378.

3. Fukushima A, Okada Y, Tanikawa T, Kawahara C, Misawa H, Kanda K, Morita E, Sasano H, Tanaka Y: Virilizing adrenocortical adenoma with Cushing's syndrome, thyroid papillary carcinoma and hypergastrinemia in a middle-aged woman. Endocr J 2003, 50:179-187.

4. Wanta SM, Basina M, Chang SD, Chang DT, Ford JM, Greco R, Kingham K, Merritt RE, Kunz PL: A rare case of an aldosterone secreting metastatic adrenocortical carcinoma and papillary thyroid carcinoma in a 31-yearold male. Rare Tumors 2011, 3:45.

5. Casula G, Angioy F, Sirigu P, Sirigu F: Carcinoma of the thyroid gland, adenoma of the adrenal cortex and peptic ulcer: an unreported association. Tumori 1976, 62:665-672.

6. Dackiw AP, Lee JE, Gagel RF, Evans DB: Adrenal cortical carcinoma. World J Surg 2001, 25:914-926.

7. Luton JP, Cerdas S, Billaud L, Thomas G, Guilhaume B, Bertagna X, Laudat MH, Louvel A, Chapuis Y, Blondeau P, Bonnin A, Bricaire $H$ : Clinical features of adrenocortical carcinoma, prognostic factors, and the effect of mitotane therapy. N Engl J Med 1990, 322:1195-1201. 
8. Wooten MD, King DK: Adrenal cortical carcinoma: epidemiology and treatment with mitotane and a review of the literature. Cancer 1993, 72:3145-3155.

9. Pohlink C, Tannapfe A, Eichfeld U, Schmidt F, Führer D, Paschke R, Koch CA: Does tumor heterogeneity limit the use of the Weiss criteria in the evaluation of adrenocortical tumors? J Endocrinol Invest 2004, 27:565-569

10. Soon PSH, McDonald KL, Robinson BG, Sidhu SB: Molecular markers and the pathogenesis of adrenocortical cancer. Oncologist 2008, 13:548-561.

11. Koch CA, Pacak K, Chrousos GP: The molecular pathogenesis of hereditary and sporadic adrenocortical and adrenomedullary tumors. J Clin Endocrinol Metab 2002, 87:5367-5384.

12. Libè R, Fratticci A, Bertherat J: Adrenocortical cancer: pathophysiology and clinical management. Endocr Relat Cancer 2007, 14:13-28.

13. Hundahl SA, Fleming ID, Fremgen AM, Menck HR: A National Cancer Data Base report on 53,856 cases of thyroid carcinoma treated in the U.S., 1985-1995. Cancer 1998, 83:2638-2648.

14. American Thyroid Association (ATA) Guidelines Taskforce on Thyroid Nodules and Differentiated Thyroid Cancer, Cooper DS, Doherty GM, Haugen BR, Kloos RT, Lee SL, Mandel SJ, Mazzaferri EL, Mclver B, Pacini F, Schlumberger M, Sherman SI, Steward DL, Tuttle RM: Revised American Thyroid Association management guidelines for patients with thyroid nodules and differentiated thyroid cancer. Thyroid 2009, 19:1167-1214.

15. Koike E, Noguchi S, Yamashita H, Murakami T, Ohshima A, Kawamoto H, Yamashita H: Ultrasonographic characteristics of thyroid nodules: prediction of malignancy. Arch Surg 2001, 136:334-337.

16. Kim N, Lavertu P: Evaluation of a thyroid nodule. Otolaryngol Clin North Am 2003, 36:17-33.

17. Mandel S, Langer J, Duick DS: Ultrasound of thyroid nodules. In Thyroid Ultrasound and Ultrasound-Guided FNA. 2nd edition. Edited by Baskin HJ Jr, Duick DS, Levine RA. New York: Springer; 2008:77-95.

18. Rago T, Santini F, Scutari M, Pinchera A, Vitti P: Elastography: new developments in ultrasound for predicting malignancy in thyroid nodules. J Clin Endocrinol Metab 2007, 92:2917-2922.

19. Song HJ, Xue YL, Xu YH, Qiu ZL, Luo QY: Rare metastases of differentiated thyroid carcinoma: pictorial review. Endocr Relat Cancer 2011, 18:165-174.

20. Wagenaar N, Oosterhuis JW, Rozendaal L, Comans E, Simsek S: Adrenal metastasis from a primary papillary thyroid carcinoma. Intern Med 2008, 47:2165-2168

21. Valo I, Verrièle V, Giraud P, Lorimier G, Guyétant S, Sommelet D: Thyroid metastases of an adrenocortical carcinoma 41 years after the diagnosis of the primary tumor. Ann Pathol 2004, 24:264-267.

22. Zhang PJ, Genega EM, Tomaszewski JE, Pasha TL, LiVolsi VA: The role of calretinin, inhibin, melan-A, BCL-2, and c-kit in differentiating adrenal cortical and medullary tumors: an immunohistochemical study. Mod Pathol 2003, 16:591-597.

23. Zhang H, Bu H, Chen H, Wei B, Liu W, Guo J, Li F, Liao D, Tang Y, Zhang Z: Comparison of immunohistochemical markers in the differential diagnosis of adrenocortical tumors: immunohistochemical analysis of adrenocortical tumors. Appl Immunohistochem Mol Morphol 2008, 16:32-39.

24. Loy TS, Phillips RW, Linder CL: A103 immunostaining in the diagnosis of adrenal cortical tumors: an immunohistochemical study of 316 cases. Arch Pathol Lab Med 2002, 126:170-172.

25. Fischer S, Asa SL: Application of immunohistochemistry to thyroid neoplasms. Arch Pathol Lab Med 2008, 132:359-372.

26. Srodon M, Westra WH: Immunohistochemical staining for thyroid transcription factor-1: a helpful aid in discerning primary site of tumor origin in patients with brain metastases. Hum Pathol 2002, 33:642-645.

27. Roh MS, Hong SH: Utility of thyroid transcription factor-1 and cytokeratin 20 in identifying the origin of metastatic carcinomas of cervical lymph nodes. J Korean Med Sci 2002, 17:512-517.

28. Bejarano PA, Nikiforov YE, Swenson ES, Biddinger PW: Thyroid transcription factor-1, thyroglobulin, cytokeratin 7, and cytokeratin 20 in thyroid neoplasms. Appl Immunohistochem Mol Morphol 2000, 8:189-194.

doi:10.1186/1752-1947-7-200

Cite this article as: Karakose et al:: A rare coexistence of non-functional adrenocortical carcinoma and multicentric papillary thyroid microcarcinoma: a case report. Journal of Medical Case Reports 2013 7:200.

\section{Submit your next manuscript to BioMed Central and take full advantage of:}

- Convenient online submission

- Thorough peer review

- No space constraints or color figure charges

- Immediate publication on acceptance

- Inclusion in PubMed, CAS, Scopus and Google Scholar

- Research which is freely available for redistribution 